\title{
Proceeding
}

Supplementary Issue: Autumn Conferences of Sports Science. Costa Blanca Sports Science Events, 18-19 December 2020. Alicante, Spain.

\section{Anthropometric characterization and muscle strength parameters in young female swimmers at national level: The relationship with performance in the $50 \mathrm{~m}$ freestyle}

\author{
DANIEL A. MARINHO ${ }^{1,2}$, HENRIQUE P. NEIVA ${ }^{1,2}$, LUÍS BRANQUINHO1, RICARDO FERRAZ1,2 \\ ${ }^{1}$ Department of Sport Sciences, University of Beira Interior, Covilhã, Portugal \\ ${ }^{2}$ Research Center in Sport Sciences, Health Sciences and Human Development (CIDESD), Portugal
}

\begin{abstract}
The aim of this study was to characterize and compare the anthropometric characteristics and the explosive muscular strength of the upper and lower limbs in swimmers at the U-16 and U-15 level. In addition, the relationship between anthropometric characteristics, strength variables and performance in the $50 \mathrm{~m}$ freestyle was verified. All participants were analysed, regarding their anthropometric characteristics, their explosive muscle strength, and their performance in the $50 \mathrm{~m}$ freestyle swim. A total of 92 female swimmers (mean \pm standard deviation: $14.08 \pm 0.56$ years old) participated in the study. The results showed that sub-16 swimmers had higher body mass values compared to sub-15 swimmers $(p<.01)$. In addition, statistically significant differences were also found for upper limb strength indicators $(p<.05)$. Finally, although no differences were found for performance in the $50 \mathrm{~m}$ freestyle test between the groups analysed, it was found that swimmers swam with different biomechanical patterns. It was concluded that although there were significant differences for the anthropometric indicators and explosive strength variables, the performance in the $50 \mathrm{~m}$ freestyle did not show any statistically significant variations, however the two groups of swimmers, swam with different biomechanical patterns.

Keywords: Young swimmers; Anthropometric characteristics; Swimming performance; Explosive strength; Biomechanical patterns.

Cite this article as:

Marinho, D.A., Neiva, H.P., Branquinho, L., \& Ferraz, R. (2021). Anthropometric characterization and muscle strength parameters in young female swimmers at national level: The relationship with performance in the $50 \mathrm{~m}$ freestyle. Journal of Human Sport and Exercise, 16(2proc), S295-S306. doi:https://doi.org/10.14198/jhse.2021.16.Proc2.15

Corresponding author. University of Beira Interior, Department of Sport Sciences. Convento de Santo António, 6201-001 Covilhã, Portugal. https://orcid.org/0000-0002-7530-512X

E-mail: ricardompferraz@gmail.com

Abstract submitted to: Autumn Conferences of Sports Science. Costa Blanca Sports Science Events, 18-19 December 2020. Alicante, Spain.

JOURNAL OF HUMAN SPORT \& EXERCISE ISSN 1988-5202

(C) Faculty of Education. University of Alicante

doi:10.14198/jhse.2021.16.Proc2.15
\end{abstract}




\section{INTRODUCTION}

Over the past few years, there has been growing interest in the determinants of competitive performance in swimming (Franken et al., 2007; Geladas et al., 2005; Marinho et al., 2011; Vantorre et al., 2014). Swimming is characterized as a complex modality, where the economy of movement, muscular strength, speed of displacement, reaction time, and ability to overcome difficulties inherent in the physical and mental processes of training and competition positively or negatively influence the gain in sports performance (Ferreira et al., 2012). Thus, swimming is associated with several factors (i.e., anthropometric, biomechanical, energetic, hydrodynamic) that are considered to be determinants of performance and are fundamental to the sport (Franken et al., 2008). In fact, evidence regarding the importance of these factors has emerged in younger swimmers, considering the constant morphological changes that occur at different ages (Garrido et al., 2010) and, consequently, in swimmers' motor performance (Aktug et al., 2019). Thus, there is a need for greater knowledge about the effects of growth and development when analysing the performance of young swimmers.

Previous studies have documented the importance of anthropometric factors in predicting performance in young swimmers (Lätt et al., 2010; Morais et al., 2012; Sammoud et al., 2018a). The anthropometric characteristics of swimmers are closely related to each other, and they play an important role in sports performance (Fernandes et al., 2002; Morais et al., 2013; Schneider and Meyer, 2005b; Zuniga et al., 2011). These characteristics exert a decisive influence in terms of propulsive capacity and the ability to overcome the drag forces encountered by the swimmer in the aquatic environment (Toussaint \& Beek, 1992) and, consequently, on swimming speed. According to what was described in a previous investigation (Morais et al., 2013), the swimmers with the best performance are tall and have large areas of frontal surface and better stroke mechanics, regardless of gender. According to Jürimäe et al. (2007) and Morais et al. (2017) wingspan is one of the best predictor and determinate variables of performance. In addition, fat mass is also an important feature of body composition that seems to vary between sports. Normally, the lower the fat mass, the better the performance (Martínez et al., 2011). However, swimming seems to be an exception, because advantages associated with a higher proportion of fat mass have been reported, such as greater buoyancy, which results in less energy expenditure (Fernandes et al., 2002; Wells et al., 2006; Zuniga et al., 2011). In this regard, female swimmers seem to have an advantage, according to what has previously been reported (Fernandes et al., 2002; Greco and Denadai, 2005; Rodrigues et al., 2001; Wells et al., 2006) because they have a greater amount of fat mass than do male swimmers. Moreover, young athletes at a highly competitive level also present higher values of gestural frequency (GF) (Craig and Pendeegast, 1979), cycle distance (CD), and swimming index (SI) (Lätt et al., 2009, 2010; Morais et al., 2013), which are excellent predictors of performance (Anderson et al., 2006; Caputo et al., 2000; Franken et al., 2007; Jürimäe et al., 2007; Lätt et al., 2009).

However, performance is also strongly related to muscle strength and power. The ability to apply force in the aquatic environment is a crucial factor for success during competition (Aspenes and Karlsen, 2012; Crowley et al., 2017; West et al., 2011), particularly over short distances (i.e., the $50 \mathrm{~m}$ freestyle). In fact, a previous study indicated that the strength and power characteristics of the lower limbs were predictors of swimming performance (West et al., 2011) and allowed for distinguishing swimmers with different levels of performance (Jones et al., 2018). Furthermore, other studies have shown a positive correlation between muscle strength or the power of the upper limbs and swimming performance (Garrido et al., 2010; Shimonogatae et al., 2003). This topic still needs further investigation, mainly in young female swimmers, as most of the existing studies focus on male swimmers. 
Studies have reported a strong association between anthropometric characteristics, strength, power, and performance in pure sports swimming, however, to the best of our knowledge, there is a gap in the literature regarding studies carried out exclusively with swimmers of different competitive levels (i.e., U-16 vs. U-15), and therefore more research is needed. Although previous studies (Geladas et al., 2005; Jürimäe et al., 2007; Nevill et al., 2015; Sammoud et al., 2018b; Morais et al., 2013; Zuniga et al., 2011) have inferred the importance of anthropometric characteristics for swimming performance for different age groups and the influence of strength in short duration tests (Aspenes and Karlsen, 2012; Crowley et al., 2017), the effects of some variables and their relationship to performance remains unclear. Thus, the main objective of this study is to characterize and compare the anthropometric characteristics (i.e., height, body mass, and wingspan) and the explosive muscular strength of the upper and lower limbs in swimmers from the U-16 and U-15 levels. In addition, we seek to verify the relationship between the anthropometric characteristics, the strength variables evaluated, and the performance in the $50 \mathrm{~m}$ freestyle, to infer how these variables can be determinant of sports performance in swimmers of the analysed levels.

\section{METHODS AND MATERIALS}

\section{Study design}

The present study is a cross-sectional study that is intended to characterize and compare the anthropometric characteristics and explosive muscle strength in female swimmers in youth groups (i.e., U-15 and U-16). In addition, we seek to understand how these characteristics can be determinant in sports performance in the youth group, and to verify their relationship with the $50 \mathrm{~m}$ freestyle competition. Thus, all participants were analysed for height, body mass, wingspan, and performance in the $50 \mathrm{~m}$ freestyle (i.e., time and biomechanical variables), as well as for the explosive strength of their lower and upper limbs.

\section{Subjects}

Ninety-two female swimmers at the national level participated in the study, aged between 13 and 15 years old (mean \pm standard deviation: $14.08 \pm 0.56$ years old). Forty-six swimmers belonged to level U-16 (14.56 \pm 0.29 years) and the remaining forty-six were members of level $U-15$ (13.61 \pm 0.28 years). The age classification system of the national competition rules for pure sports swimming of the Portuguese Swimming Federation (FPN) was used as a reference. The participating subjects were chosen, as they were participants of the internships carried out by the FPN, which took place between the years 2014 and 2018, in which the swimmers with the best score in the final classification of the previous season were included. The sample consisted of practitioners who were familiar with the competitive practice of pure swimming and familiar with the ballistic exercises used. All participants were fully informed verbally and in writing about the nature of the study, as well as the known health risks. The participants filled out a questionnaire about their health history and were informed that they could withdraw from the study at any time. All parents provided their informed consent, attesting to their children's voluntary participation in the study. The study was approved by the school's Ethical Advisory Committee and conducted in accordance with the Declaration of Helsinki.

\section{Procedures}

The evaluations were carried out during the internship period, which comprised 2 days and 4 training and evaluation sessions. All individuals were evaluated at the same time of the sports season (October). The evaluation sessions were spread over the two days of the internship, and the anthropometric tests, which did not require energy expenditure and did not incur fatigue, were carried out before the strength and performance tests. In addition, the tests were performed to ensure sufficient rest between sessions, so that no fatigue was accumulated that could negatively influence the swimmers' performance. 
On the day of the assessment, the anthropometric measurements of each subject (i.e., such as body mass, height, wingspan, and subsequently the wingspan/height indexes were calculated) were taken after 5 minutes of rest. Then, a strength evaluation of the lower limbs was performed through the horizontal jump. In the afternoon session, an assessment of the strength of the upper limbs was performed by throwing a medicine ball.

\section{Anthropometric measures}

All measures were obtained before any physical performance test and were assessed according to international standards for anthropometric assessment (Marfell-Jones et al., 2006). Participants were barefoot and dressed in underwear or as little clothing as possible during the assessment. To measure body height (in meters), a precision stadiometer with a scale of $0.001 \mathrm{~m}$ was used. BMI was obtained by dividing the body mass value by the square of height. Wingspan was determined by measuring the athletes with a tape measure placed on a precision wall at a scale of $0.001 \mathrm{~m}$.

\section{Strength assessment of the upper and lower limbs}

To evaluate the strength of the lower limbs, horizontal thrust exercises were performed. Three jumps were used for each assessment per subject, with a two-minute rest between each jump. When performing the jump, a tape measure was placed on the floor. The swimmers had to stand at the end of the tape measure with their feet shoulder-width apart. When performing the jump, the swimmers could move their upper limbs before the impulse. Values were recorded in meters. For the analysis, the average of the three jumps and the best jump performed were recorded. The national technical director assisted in verifying the correct position of the swimmers during the execution of each jump. The reliability of the horizontal jump was determined by the intraclass correlation coefficient (ICC), with mean values of 0.99 and a coefficient of variation (CV) of $2.56 \%$.

The medicine ball launch was measured by the horizontal distance reached by a $3 \mathrm{~kg}$ ball after it was launched. To perform the evaluation, each subject sat on the floor with their back against a rectilinear structure (wall). Each participant held the ball in front of them with both hands (close to the chest) to achieve the greatest amplitude, speed, and distance possible without rotating the torso or hips during the execution of the movement. Two experienced evaluators assisted in verifying the launch, as well as the obtained range. Three attempts were counted with a $3 \mathrm{~kg}$ medicine ball, with a one-minute rest period between each throw. The distance from the starting position to where the ball touched the ground was measured (Castro-Piñero et al., 2009). Overall, the launch of the medicine ball showed an average ICC of 0.98 , and the CV values were $1.98 \%$.

\section{Swimming performance evaluation}

After performing a $1000 \mathrm{~m}$ warm-up using the usual structure based on the protocols described by Neiva et al. (2014), each swimmer performed a simulated race $(50 \mathrm{~m}$ or $400 \mathrm{~m})$. The evaluation protocols, including departure from the block and an official announcer, were applied in a $25 \mathrm{~m}$ covered swimming pool at an average temperature of $28{ }^{\circ} \mathrm{C}$ and an average humidity below $70 \%$. The time was recorded using a stopwatch (Finis 3x100 Stopwatch, Livermore, California). The swims were also filmed and subsequently analysed using the software program Kinovea ${ }^{\circledR}$ version 0.8 .15 . The reliability of the test performed was analysed using the ICC. A value of 0.92 was obtained, thus the average value was used for further analysis. Biomechanical variables were evaluated for both simulations. A measurement of GF was performed using a chronometer in three stroke cycles, which was later converted to units of measurement in the international system (Hz). CD was measured by estimation using the following equation (Craig and Pendeegast, 1979): 


$$
\mathrm{CD}=v / \mathrm{GF}
$$

where $\mathrm{CD}$ is the cycle distance $\left(\mathrm{m} \mathrm{c}^{-1}\right)$, $\mathrm{v}$ is the average speed of the swimmer $\left(\mathrm{m} \mathrm{s}^{-1}\right)$, and $\mathrm{GF}$ is the gestural frequency of swimming. SI was then estimated using the following equation (Costill et al., 1985):

$$
S I=C D \times v
$$

where SI represents the swimming index $\left(\mathrm{m}^{2} \mathrm{c}^{-1} \mathrm{~s}^{-1}\right), \mathrm{CD}$ is the distance per cycle $\left(\mathrm{m} \mathrm{c}^{-1}\right)$, and $\mathrm{v}$ is the average swimming speed $\mathrm{m} \mathrm{s}^{-1}$ ). The speed variables FG, CD, and IN were evaluated in the second $25 \mathrm{~m}$ of each 50 $\mathrm{m}$ (either in the $50 \mathrm{~m}$ event or $400 \mathrm{~m}$ event) and were used to determine the average measure in the $400 \mathrm{~m}$ freestyle swim. To analyse these variables, the program Kinovea ${ }^{8}$ (version 0.8.15) was used.

\section{Statistical analysis}

Data analysis was performed using the statistical software IBM SPSS (Statistical Package for Social Sciences), version 22.0, for Microsoft Windows (Armonk, NY, EU: IBM Corp.). The level of significance was set at $5 \%$. The calculation of means, standard deviations, differences, and confidence intervals $(95 \% \mathrm{Cl})$ were performed using standardized statistical methods. Reliability was measured by the CV and ICC in the three tests performed for the launch of the medicine ball. The horizontal jump was calculated with the bidirectional mixed random effects model (a type of absolute agreement). The normality of the distribution was verified using the Kolmogorov-Smirnov test $(n>30)$, and it was found that the data had a normal distribution. Thus, parametric tests were used for data analysis. To compare between the results obtained for the U-16 and U-15, the t-test for independent samples was used. Pearson's coefficient was used for the bivariate correlations, and the determination coefficient $\left(\mathrm{r}^{2}\right)$ was also calculated. The ratio was considered extremely high for values between .90 and 1.00 , high for values between .70 and .90 , moderate between .50 and .70 , low for values between .30 and .50 and between .10 and .30 was considered small.

\section{RESULTS}

Table 1 shows the values for the anthropometric characteristics evaluated in the U-16 and U-15 groups of swimmers. Of the studied variables, there is a difference in the body weight values between the two groups.

Table 1. Comparison between the mean values ( \pm standard deviation) of the anthropometric variables for

\begin{tabular}{|c|c|c|c|c|c|}
\hline \multirow{2}{*}{ Variables } & \multirow{2}{*}{$U-16(n=46)$} & \multirow{2}{*}{$U-15(n=46)$} & \multicolumn{2}{|c|}{ Difference (Cl 95\%) } & \multirow{2}{*}{$p$-value } \\
\hline & & & Lower & Higher & \\
\hline Height (m) & $1.64 \pm 0.06$ & $1.63 \pm 0.05$ & -0.01 & 0.04 & .17 \\
\hline Weight (kg) & $54.64 \pm 4.51$ & $52.11 \pm 5.14$ & 0.53 & 4.53 & $.01^{* *}$ \\
\hline Body mass index $\left(\mathrm{kg} / \mathrm{m}^{2}\right)$ & $20.22 \pm 1.47$ & $19.63 \pm 1.47$ & -0.01 & 1.20 & .06 \\
\hline Wingspan $(\mathrm{m})$ & $1.66 \pm 0.07$ & $1.65 \pm 0.06$ & -0.02 & 0.04 & .36 \\
\hline Wingspan / height index & $1.01 \pm 0.03$ & $1.01 \pm 0.03$ & -0.02 & 0.01 & .78 \\
\hline
\end{tabular}
juveniles $A$ and juveniles $B$. The $p$-values and the confidence interval $(\mathrm{Cl})$ of the difference are also presented.

To compare the values related to muscle performance, Table 2 shows the values of muscle strength of the upper and lower limbs. It is evident that the U-16 swimmers, who are the most experienced, achieve higher launch values for the medical ball than the U-15 swimmers. 
Table 2. Comparison between the mean values ( \pm standard deviation) of the muscle strength variables for $\mathrm{U}-16$ and $\mathrm{U}-15$. The $\mathrm{p}$-values and $\mathrm{Cl}$ interval of the difference are also presented.

\begin{tabular}{|c|c|c|c|c|c|}
\hline \multirow{2}{*}{ Variables } & \multirow{2}{*}{$U-16(n=46)$} & \multirow{2}{*}{$U-15(n=46)$} & \multicolumn{2}{|c|}{ Difference (CI 95\%) } & \multirow{2}{*}{$p$-value } \\
\hline & & & Lower & Higher & \\
\hline Horizontal jump - average (m) & $1.72 \pm 0.17$ & $1.69 \pm 0.20$ & -0.05 & 0.11 & .45 \\
\hline Horizontal jump - maximum (m) & $1.78 \pm 0.18$ & $1.74 \pm 0.21$ & -0.04 & 0.12 & .33 \\
\hline Medium medical ball throw (m) & $3.25 \pm 0.35$ & $3.13 \pm 0.45$ & -0.05 & 0.28 & .17 \\
\hline Maximum medical ball throw (m) & $3.44 \pm 0.37$ & $3.26 \pm 0.46$ & 0.01 & 0.36 & $.04^{*}$ \\
\hline
\end{tabular}

In relation to swimming performance, it is evident that no significant differences were detected between the two groups under analysis. However, differences were found in the biomechanical variables analysed. The U-16 swimmers recorded a lower GF and a higher $\mathrm{CD}$, and they completed the $50 \mathrm{~m}$ freestyle with a higher SI than the U-15 swimmers.

Table 3. Comparison between the mean values ( \pm standard deviation) of the swimming performance variables in the $50 \mathrm{~m}$ freestyle, as well as the values of gestural frequency (GF), cycle distance (CD), and swimming index $(\mathrm{SI})$. The $p$-values and confidence intervals are also presented.

\begin{tabular}{|c|c|c|c|c|c|}
\hline \multirow{2}{*}{ Variables } & \multirow{2}{*}{$U-16(n=46)$} & \multirow{2}{*}{$U-15(n=46)$} & \multicolumn{2}{|c|}{ Difference (CI 95\%) } & \multirow{2}{*}{$p$-value } \\
\hline & & & Lower & Higher & \\
\hline $50 \mathrm{~m}$ freestyle (s) & $30.98 \pm 1.08$ & $31.35 \pm 1.25$ & -0.02 & 0.01 & .14 \\
\hline $\mathrm{GF}(\mathrm{Hz})$ & $49.12 \pm 5.47$ & $51.02 \pm 4.33$ & -3.76 & -0.05 & $.04^{*}$ \\
\hline $\mathrm{CD}\left(\mathrm{m} \mathrm{c}^{-1}\right)$ & $1.95 \pm 0.19$ & $1.85 \pm 0.18$ & 0.02 & 0.18 & $.02^{*}$ \\
\hline$S I\left(m^{2} c^{-1} s^{-1}\right)$ & $3.09 \pm 0.38$ & $2.90 \pm 0.35$ & 0.04 & 0.34 & $.01^{* *}$ \\
\hline
\end{tabular}

Confidence Interval $(C l):{ }^{*} p<.05 ;{ }^{* *} p<.01$.

Regarding the correlations between anthropometric variables and swimming performance in the $50 \mathrm{~m}$ freestyle, significant values were found in the case of height $(r=-0.23, p=.03)$, body mass $(r=-0.33, p=$ $.001)$ and wingspan $(r=-0.27, p=.01)$. Figure 1 shows the relationship between anthropometric variables and the time in the $50 \mathrm{~m}$ freestyle.
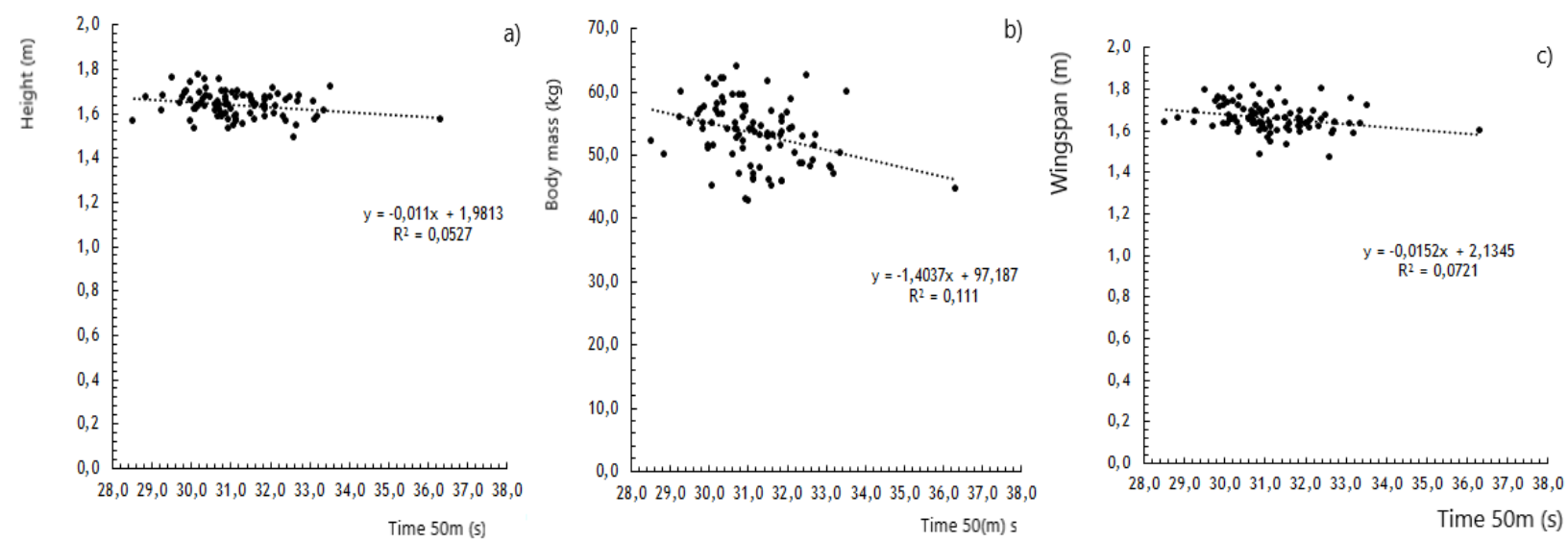

Figure 1. Graphical representation of the relationship between the time in the $50 \mathrm{~m}$ freestyle and height (a), body mass (b), and wingspan (c). 
Figure 2 shows the relationship between muscle strength variables, namely the horizontal jump and the launch of the medicine ball, and the swimming performance in the $50 \mathrm{~m}$ freestyle. There were significant relationships between swimming performance and the horizontal jump $(r=-0.44, p<.01)$ and between swimming performance and the throw of the medicine ball $(r=0.27, p=.01)$.
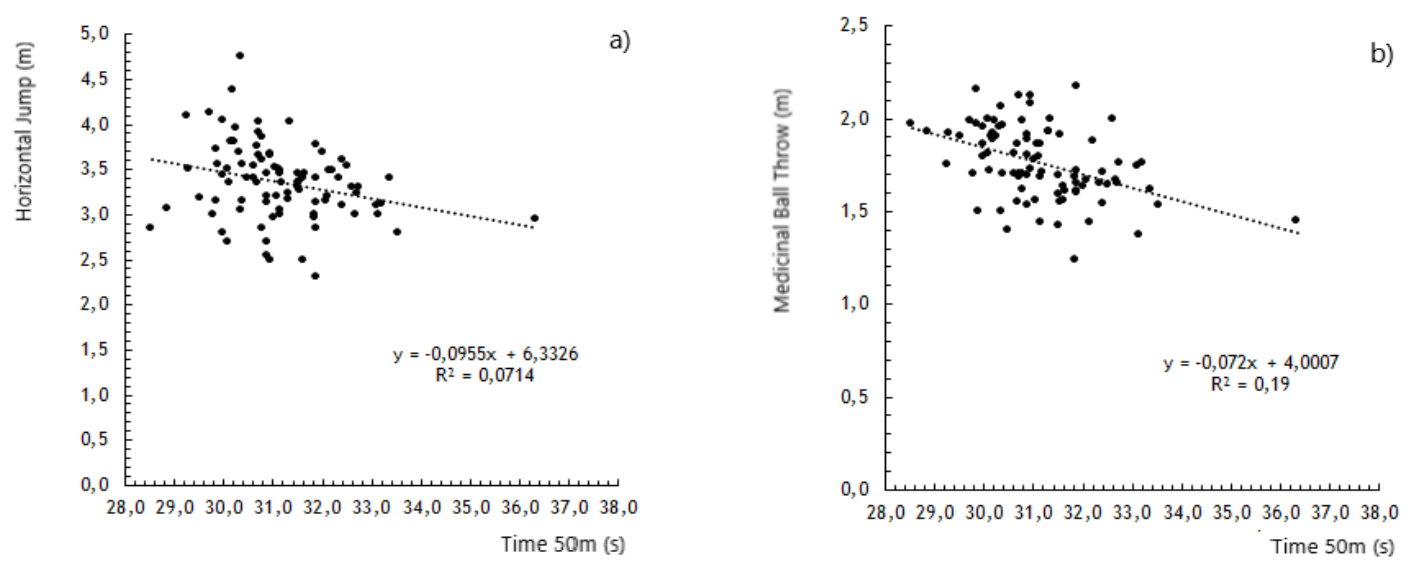

Figure 2. Graphical representation of the relationship between the $50 \mathrm{~m}$ freestyle time and the maximum values of the horizontal jump (a) and the medicine ball throw (b).

\section{DISCUSSION}

The present study aimed to characterize and compare the anthropometric characteristics (i.e., height, body mass, and wingspan) and the explosive muscular strength of the upper and lower limbs of swimmers in the U-16 and U-15 groups. In addition, we sought to analyse the relationship between anthropometric characteristics, the strength variables evaluated, and performance in the $50 \mathrm{~m}$ freestyle to understand how these variables can be determinant of sports performance in young swimmers.

The U-16 swimmers showed higher body mass values than the U-15 swimmers and regarding the strength variables, the U-16 swimmers showed higher maximum values when throwing the medicine ball, which is in line with a previous investigation (Garrido, et al., 2010; Yanai, 2003). Although there were no statistically significant differences between the performance values in the groups analysed, it was found that the swimmers performed the $50 \mathrm{~m}$ freestyle with different biomechanical swimming patterns. Barbosa et al. (2010) stated that a swimmer adjusts their technical standard, measured by the swimming distance and the GF, in order to be as efficient as possible according to the swimmer's physical condition and the existing context. The U-16 swimmers recorded higher CD and lower GF values, with a higher SI. In this way, it was possible to conclude that the U-16 swimmers demonstrated greater technical efficiency, although their performance did not show a statistically significant difference from the U-15 swimmers. Furthermore, it was found that the height, body mass, wingspan, and muscle strength of the lower and upper limbs were related to performance in the $50 \mathrm{~m}$ freestyle.

From the U-16 and U-15 categories, it was observed (Table 1) that there were significant differences in terms of anthropometric variables, with U-16 swimmers presenting higher values than U-15 swimmers for variables such as height, weight, body mass and wingspan. In addition, a previous study (Fernandes et al., 2002) concluded that the greater the length of the upper and lower limbs, the more efficient a swimmer would be, given that they would need a smaller number of motor actions to cover a certain distance, which was directly associated with muscle strength and performance in the $50 \mathrm{~m}$ freestyle. However, this assumption was not 
verified in our study because although there were differences in anthropometric characteristics, these did not translate to significant differences in $50 \mathrm{~m}$ freestyle swim performance. This factor may be due to the fact that the U-16 swimmers had not yet reached their peak of growth and maturation (Malina, 2006; Veldhuis et al., 2005).

Muscle strength training is important for swimmers' sport performance (Muniz-Pardos et al., 2019; Sammoud et al., 2019; Schneider and Meyer, 2005a). The analysis of Table 2 seems to demonstrate that U-16 swimmers have better results than U-15 swimmers with respect to upper limb strength. For swimmers to move in the aquatic environment, they must propel themselves through the actions of the lower and upper limbs. Thus, it is important that swimmers perform strength training that will allow them to increase their ability to move and propel the upper limbs in the water environment (Hawley et al., 1992; Marques et al., 2020). Furthermore, strength training combined with swimming training shows better results for swimmers than swimming training alone (Amaro et al., 2017). In fact, strength training combined with swimming training allows swimmers to show significant improvements, making them faster when they have to cover distances such as $50 \mathrm{~m}$ (Lopes et al., 2020). This correlation is shown in Figure 2, where there are significant improvements in the swimmers with strength training.

Strength training out of the water should be performed so that there is complementary development in water with the movements that swimmers perform during the swim (Mujika and Crowley, 2019). Thus, it can be concluded that strength training increases the gain in strength in the upper and lower limbs, which can lead to an increase in the performance of the swimmers.

GF is determined by dividing the number of strokes by the swimming time in minutes. Thus, when swimmers have a high GF it means that they have a high energy expenditure and become fatigued quickly (Smith et al., 1988). The $C D$ is obtained by dividing the swimming distance by the number of cycles. Thus, there must be propulsive force, so that there is use of energy (Toussaint, 1990). The U-16 swimmers have a higher CD value than the $\mathrm{U}-15$ swimmers, which may be related to the fact that they have superior propulsive efficiency (Toussaint et al., 2006). Furthermore, the strength of the upper limbs in these swimmers was superior, as noted above, which might have contributed to a higher $\mathrm{CD}$, but mainly contributed to higher SI values. $\mathrm{SI}$ is obtained by multiplying the swimming speed by the CD. U-16 swimmers had a higher SI than U-15 swimmers, which may indicate they have superior technical swimming efficiency.

Table 3 shows that U-16 swimmers perform better than U-15 swimmers, however without statistically significant differences $(p \geq 0,5)$. The results presented suggest that strength training can improve the performance of swimmers with regard to the propulsion of upper and lower limbs. In addition, these data also confirm that U-16 swimmers may not have reached full maturity, which conflicts with what was previously reported (Malina and Geithner, 2011). According to Pelayo et al., (1996), the anthropometric factors are related to the results of the $50 \mathrm{~m}$ distance tests. Factors such as swimmers' wingspan and height are important to reducing fatigue for swimmers. It is concluded, therefore, that there is a relationship between anthropometric factors and the $50 \mathrm{~m}$ performance (Figure 1). It can be concluded that to improve swimming performance, it is important that trainers include a strength component in the training, but also consider the factors of swimming performance (GF, SI, and swimming distance).

\section{CONCLUSION}

The results of this study allowed us to conclude that i) the U-16 swimmers showed higher values for body mass and explosive strength of the upper limbs than the U-15 swimmers; ii) although there were no 
differences between the performance values in the analysed groups, it was found that the swimmers performed the $50 \mathrm{~m}$ freestyle by swimming with different biomechanical patterns. In addition, the U-16 level recorded higher CD and lower GF values, which indicated greater technical efficiency; iii) the performance in the $50 \mathrm{~m}$ freestyle event is related to height, body mass, wingspan, and muscular strength of the lower and upper limbs in the two groups analysed. Future studies may include swimming tests with other distances and styles for analysis in swimmers at different competitive levels.

\section{ACKNOWLEDGMENTS}

This work is supported by national funding through the Portuguese Foundation for Science and Technology, I.P., under project UID04045/2020.

\section{REFERENCES}

Aktug, Z. B., Vural, Ş. N., \& İbis, S. (2019). The Effect of Theraband Exercises on Motor Performance and Swimming Degree of Young Swimmers1. Turkish J. Sport Exerc., 21(2), 238-243. https://doi.org/10.15314/tsed.578524

Amaro, N. M., Marinho, D. A., Marques, M. C., Batalha, N. P., \& Morouço, P. G. (2017). Effects of DryLand Strength and Conditioning Programs in Age Group Swimmers. J. Strength Cond. Res., 31(9), 2447-2454. https://doi.org/10.1519/JSC.0000000000001709

Anderson, M. E., Hopkins, W. G., Roberts, A. D., \& Pyne, D. B. (2006). Monitoring seasonal and longterm changes in test performance in elite swimmers. Eur. J. Sport Sci., 6(3), 145-154. https://doi.org/10.1080/17461390500529574

Aspenes, S. T., \& Karlsen, T. (2012). Exercise-training intervention studies in competitive swimming. Sport. Med., 42(6), 527-543. https://doi.org/10.2165/11630760-000000000-00000

Barbosa, T. M., Costa, M., Marinho, D. A., Coelho, J., Moreira, M., \& Silva, A. J. (2010). Modeling the links between young swimmers' performance: Energetic and biomechanic profiles. Pediatr. Exerc. Sci., 22(3), 379-391. https://doi.org/10.1123/pes.22.3.379

Caputo, F., de Lucas, R. D., Greco, C. C., \& Denadai, B. S. (2000). Características da braçada em diferentes distâncias no estilo crawl e correlaçöes com a performance. Rev. Bras. Ciênc. Mov, 8(3), 7-13. https://doi.org/10.18511/rbcm.v8i3.363

Castro-Piñero, J., González-Montesinos, J. L., Mora, J., Keating, X. D., Girela-Rejón, M. J., Sjöström, M., \& Ruiz, J. R. (2009). Percentile values for muscular strength field tests in children aged 6 to 17 years: influence of weight status. J. Strength Cond. Res., 23(8), 2295-2310. https://doi.org/10.1519/JSC.0b013e3181b8d5c1

Costill, D. L., Kovaleski, J., Porter, D., Kirwan, J., Fielding, R., \& King, D. (1985). Energy expenditure during front crawl swimming: Predicting success in middle-distance events. Int. J. Sports Med., 6(5), 266-270. https://doi.org/10.1055/s-2008-1025849

Craig, A. B., \& Pendeegast, D. R. (1979). Relationships of stroke rate, distance per stroke, and velocity in competitive swimming. Med. Sci. Sports Exerc., 11(3), 278-283. https://doi.org/10.1249/00005768197901130-00011

Crowley, E., Harrison, A. J., \& Lyons, M. (2017). The Impact of Resistance Training on Swimming Performance: A Systematic Review. Sport. Med., 47(11), 2285-2307. https://doi.org/10.1007/s40279-017-0730-2

Fernandes, R., Barbosa, T., \& Vilas-Boas, J. P. (2002). Fatores cineantropométricos determinantes em natação pura desportiva. Rev. Bras. Cineantropometria e Desempenho Hum., 4(1), 67-79. 
Ferreira, M. I., Silva, A. J., Oliveira, D. R. de, Garrido, N. D., Barbosa, T., Marinho, D. A., \& Reis, V. M. (2012). Analysis of the determinant kinematical parameters for performance in the 200-m freestyle swimming event. Mot. Rev. Educ. Fis., 18(2), 366-377. https://doi.org/10.1590/S198065742012000200017

Franken, M., Carpes, F. P., Diefenthaeler, F., \& Castro, F. A. de S. (2008). Relação entre cinemática e antropometria de nadadores recreacionais e universitários TT - Kinematics and anthropometric relationship between recreational and college swimmers. Mot. Rev. Educ. Fís., 14(3), 329-336.

Franken, M., Pivetta, F., \& Antônio De Souza, F. (2007). Cinematica do nado crawl, caracteristicas antropometicas e flexibilidade de nadadores universitarios. Cbce, 15, 8 .

Garrido, N., Marinho, D. A., Barbosa, T. M., Costa, A. M., Silva, A. J., Pérez-Turpin, J. A., \& Marques, M. C. (2010). Relationships between dry land strength, power variables and short sprint performance in young competitive swimmers. J. Hum. Sport Exerc., II, 240-249. https://doi.org/10.4100/jhse.2010.52.12

Garrido, N., Marinho, D. A., Reis, V. M., van den Tillaar, R., Costa, A. M., Silva, A. J., \& Marques, M. C. (2010). Does combined dry land strength and aerobic training inhibit performance of young competitive swimmers? J. Sport. Sci. Med., 9(2), 300-310.

Geladas, N. D., Nassis, G. P., \& Pavlicevic, S. (2005). Somatic and physical traits affecting sprint swimming performance in young swimmers. Int. J. Sports Med., 26(2), 139-144. https://doi.org/10.1055/s-2004-817862

Greco, C. C., \& Denadai, B. S. (2005). Critical speed and endurance capacity in young swimmers: Effects of gender and age. Pediatr. Exerc. Sci., 17(4), 353-363. https://doi.org/10.1123/pes.17.4.353

Hawley, J. A., Williams, M. M., Vickovic, M. M., \& Handcock, P. J. (1992). Muscle power predicts freestyle swimming performance. Br. J. Sports Med., 26(3), 151-155. https://doi.org/10.1136/bjsm.26.3.151

Jones, J. V., Pyne, D. B., Greg Haff, G., \& Newton, R. U. (2018). Comparison between elite and subelite swimmers on dry land and tumble turn leg extensor force-time characteristics. J. Strength Cond. Res., 32(6), 1762-1769. https://doi.org/10.1519/jsc.0000000000002041

Jürimäe, J., Haljaste, K., Cicchella, A., Lätt, E., Purge, P., Leppik, A., \& Jürimäe, T. (2007). Analysis of swimming performance from physical, physiological, and biomechanical parameters in young swimmers. Pediatr. Exerc. Sci., 19(1), 70-81. https://doi.org/10.1123/pes.19.1.70

Lätt, E., Jürimäe, J., Haljaste, K., Cicchella, A., Purge, P., \& Jürimäe, T. (2009). Longitudinal development of physical and performance parameters during biological maturation of young male swimmers. Percept. Mot. Skills, 108(1), 297-307. https://doi.org/10.2466/PMS.108.1.297-307

Lätt, E., Jürimäe, J., Mäestu, J., Purge, P., Rämson, R., Haljaste, K., Keskinen, K. L., Rodriguez, F. A., \& Jürimäe, T. (2010). Physiological, biomechanical and anthropometrical predictors of sprint swimming performance in adolescent swimmers. J. Sport. Sci. Med., 9(3), 398-404. https://pubmed.ncbi.nlm.nih.gov/24149633

Lopes, T. J., Neiva, H. P., Gonçalves, C. A., Nunes, C., \& Marinho, D. A. (2020). The effects of dry-land strength training on competitive sprinter swimmers. J. Exerc. Sci. Fit., 19(1), 32-39. https://doi.org/10.1016/i.jesf.2020.06.005

Malina, R. M. (2006). Weight training in youth-growth, maturation, and safety: An evidence-based review. Clin. J. Sport Med., 16(6), 478-487. https://doi.org/10.1097/01.jsm.0000248843.31874.be

Malina, R. M., \& Geithner, C. A. (2011). Body composition of young athletes. Am. J. Lifestyle Med., 5(3), 262-278. https://doi.org/10.1177/1559827610392493

Marfell-Jones, M., Olds, T., Stewart, A. D., \& Lindsay Carter, J. E. (2006). International Standards for Anthropometric Assessment. In The International Society for the Advancement of Kinanthropometry (Vol. 137). https://doi.org/10.4324/9780203970157 
Marinho, D. A., Amorim, R. A., Costa, A. M., Marques, M. C., Pérez-Turpin, J. A., \& Neiva, H. P. (2011). "Anaerobic" critical velocity and swimming performance in young swimmers. J. Hum. Sport Exerc., 6(1), 80-86. https://doi.org/10.4100//hse.2011.61.09

Marques, M. C., Yáñez-García, J. M., Marinho, D. A., González-Badillo, J. J., \& Rodríguez-Rosell, D. (2020). In-Season Strength Training in Elite Junior Swimmers: The Role of the Low-Volume, HighVelocity Training on Swimming Performance. J. Hum. Kinet., 74(1), 71-84.

Martínez, S., Pasquarelli, B. N., Romaguera, D., Arasa, C., Tauler, P., \& Aguiló, A. (2011). Anthropometric characteristics and nutritional profile of young amateur swimmers. J. Strength Cond. Res., 25(4), 1126-1133. https://doi.org/10.1519/JSC.0b013e3181d4d3df

Morais, J. E., Garrido, N. D., Marques, M. C., Silva, A. J., Marinho, D. A., \& Barbosa, T. M. (2013). The influence of anthropometric, kinematic and energetic variables and gender on swimming performance in youth athletes. J. Hum. Kinet., 39(1), 203-211. https://doi.org/10.2478/hukin-2013$\underline{0083}$

Morais, J. E., Jesus, S., Lopes, V., Garrido, N., Silva, A., Marinho, D., \& Barbosa, T. M. (2012). Linking selected kinematic, anthropometric and hydrodynamic variables to young swimmer performance. Pediatr. Exerc. Sci., 24(4), 649-664. https://doi.org/10.1123/pes.24.4.649

Morais, J. E., Silva, A. J., Marinho, D. A., Lopes, V. P., \& Barbosa, T. M. (2017). Determinant factors of long-term performance development in young swimmers. Int. J. Sports Physiol. Perform., 12(2), 198205. https://doi.org/10.1123/ijspp.2015-0420

Mujika, I., \& Crowley, E. (2019). Strength training for swimmers. In Concurrent Aerobic and Strength Training (pp. 369-386). Springer. https://doi.org/10.1007/978-3-319-75547-2_25

Muniz-Pardos, B., Gomez-Bruton, A., Matute-Llorente, A., Gonzalez-Aguero, A., Gomez-Cabello, A., Gonzalo-Skok, O., Casajus, J. A., \& Vicente-Rodriguez, G. (2019). Swim-specific resistance training: a systematic review. J. Strength Cond. Res., 33(10), 2875-2881. https://doi.org/10.1519/JSC.0000000000003256

Neiva, H. P., Marques, M. C., Barbosa, T. M., Izquierdo, M., \& Marinho, D. A. (2014). Warm-up and performance in competitive swimming. Sport. Med., 44(3), 319-330. https://doi.org/10.1007/s40279013-0117-y

Nevill, A. M., Oxford, S. W., \& Duncan, M. J. (2015). Optimal body size and limb length ratios associated with 100-m personal-best swim speeds. Med. Sci. Sports Exerc., 47(8), 1714-1718. https://doi.org/10.1249/MSS.0000000000000586

Pelayo, P., Sidney, M., Kherif, T., Chollet, D., \& Tourny, C. (1996). Stroking characteristics in freestyle swimming and relationships with anthropometric characteristics. J. Appl. Biomech., 12(2), 197-206. https://doi.org/10.1123/jab.12.2.197

Rodrigues, M. N., da Silva, S. C., Monteiro, W. D., \& Farinatti, P. de T. V. (2001). Estimativa da gordura corporal através de equipamentos de bioimpedância, dobras cutâneas e pesagem hidrostática. Rev. Bras. Med. Do Esporte, 7(4), 125-131. https://doi.org/10.1590/S1517-86922001000400003

Sammoud, S., Negra, Y., Chaabene, H., Bouguezzi, R., Moran, J., \& Granacher, U. (2019). The effects of plyometric jump training on jumping and swimming performances in prepubertal male swimmers. J. Sports Sci. Med., 18(4), 805.

Sammoud, S., Nevill, A. M., Negra, Y., Bouguezzi, R., Chaabene, H., \& Hachana, Y. (2018a). 100-m breaststroke swimming performance in youth swimmers: The predictive value of anthropometrics. Pediatr. Exerc. Sci., 30(3), 393-401. https://doi.org/10.1123/pes.2017-0220

Sammoud, S., Nevill, A. M., Negra, Y., Bouguezzi, R., Chaabene, H., \& Hachana, Y. (2018b). Allometric associations between body size, shape, and 100-m butterfly speed performance. J. Sports Med. Phys. Fitness, 58(5), 630-637. https://doi.org/10.23736/S0022-4707.17.07480-1 
Schneider, P., \& Meyer, F. (2005a). Anthropometric and muscle strength evaluation in prepubescent and pubescent swimmer boys and girls. Rev. Bras. Med. Do Esporte, 11(4), 209-213. https://doi.org/10.1590/s1517-86922005000400001

Schneider, P., \& Meyer, F. (2005b). Avaliação antropométrica e da força muscular em nadadores prépúberes e púberes. Rev. Bras. Med. Do Esporte, 11(4), 209-213. https://doi.org/10.1590/s1517$\underline{86922005000400001}$

Shimonogatae, S. Taguchi, M. Miura, M. (2003). The effect of swimming power, swimming power endurance and dry-land power on 100 m freestyle performance. Biomech. Med. Swim. IX, IX, 391396.

Toussaint, H. M., \& Beek, P. J. (1992). Biomechanics of Competitive Front Crawl Swimming. Sport. Med. An Int. J. Appl. Med. Sci. Sport Exerc., 13(1), 8-24. https://doi.org/10.2165/00007256-199213010$\underline{00002}$

Toussaint, H. M., Carol, A., Kranenborg, H., \& Truijens, M. J. (2006). Effect of fatigue on stroking characteristics in an arms-only 100-m front-crawl race. Med. Sci. Sports Exerc., 38(9), 1635-1642. https://doi.org/10.1249/01.mss.0000230209.53333.31

Vantorre, J., Chollet, D., \& Seifert, L. (2014). Biomechanical analysis of the swim-start: A review. J. Sport. Sci. Med., 13(2), 223-231.

Veldhuis, J. D., Roemmich, J. N., Richmond, E. J., Rogol, A. D., Lovejoy, J. C., Sheffield-Moore, M., Mauras, N., \& Bowers, C. Y. (2005). Endocrine control of body composition in infancy, childhood, and puberty. Endocr. Rev., 26(1), 114-146. https://doi.org/10.1210/er.2003-0038

Wells, G. D., Schneiderman-Walker, J., \& Plyley, M. (2006). Normal physiological characteristics of elite swimmers. Pediatr. Exerc. Sci., 18(1), 30-52. https://doi.org/10.1123/pes.18.1.30

West, D. J., Owen, N. J., Cunningham, D. J., Cook, C. J., \& Kilduff, L. P. (2011). Strength and power predictors of swimming starts in international sprint swimmers. J. Strength Cond. Res., 25(4), 950 955. https://doi.org/10.1519/JSC.0b013e3181c8656f

Yanai, T. (2003). Stroke frequency in front crawl: its mechanical link to the fluid forces required in nonpropulsive directions. J. Biomech., 36(1), 53-62. https://doi.org/10.1016/S0021-9290(02)00299-3

Zuniga, J., Housh, T. J., Michelle, M., Hendrix, C. R., Camic, C. L., Johnson, G. O., Housh, D. J., \& Schmidt, R. J. (2011). Gender comparisons of anthropometric characteristics of young sprint swimmers. J. Strength Cond. Res., 25(1), 103-108. https://doi.org/10.1519/JSC.0b013e3181b62bf7

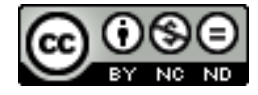

This work is licensed under a Attribution-NonCommercial-NoDerivatives 4.0 International (CC BY-NC-ND 4.0). 